\title{
RIFArtigos/Ensaios
}

DOI - 10.5212/RIF.v.19.i43.0008

\section{Ativismo Folkcomunicacional: Práticas de Comunicação e Resistência das Culturas Populares na Pandemia da Covid-19 em Sergipe}

\author{
Flávio Santana ${ }^{1}$ \\ Denio Santos Azevedo ${ }^{2}$ \\ Arisvaldo Andrade Santos Neto ${ }^{3}$
}

Submetido em: 07/09/2021

Aceito em: 16/11/2021

\section{RESUMO}

Diante dos desafios provocados pela pandemia da Covid-19 e a consequente migração da forma de consumir práticas culturais para o virtual,as lideranças das diferentes manifestações ganharam ainda mais respaldo na (re)invenção das manifestações culturais e na defesa de direitos individuais e coletivos. Frente a essa realidade, este estudo tem por objetivo analisar as práticas de comunicação e resistência utilizadas pelos ativistas das culturas populares em Sergipe do início do período pandêmico até o desenvolvimento deste estudo. Para isso, respeitou-se os lugares de fala e as vozes dos ativistas midiáticos, a partir da técnica de entrevistas semiestruturadas commestres e mestras das culturas populares do estado de Sergipe, aliadas a observações participantes. Constatou-se, por fim, a importância da mobilização dos ativistas nas mídias sociais digitais, fator condicionante para a resistência dos grupos de culturas populares e continuação destes saberes e fazeres no período trabalhado.

\section{PALAVRAS-CHAVE}

Ativismo Midiático; Culturas Populares; Folkcomunicação; Pandemia da Covid-19; Sergipe.

\footnotetext{
1 Professor substituto do Curso de Comunicação Social/Jornalismo da Universidade Estadual do Piauí (UESPI). Mestre em Comunicação Social pela Universidade Metodista de São Paulo (Umesp). Diretor Financeiro da Rede de Estudos e Pesquisa em Folkcomunicação (Rede Folkcom). Correio eletrônico: ms.flaviosantana@hotmail.com

2 Pós-doutorando no Departamento de História do Royal Military Collegeof Canada. Professor do Mestrado em Culturas Populares da Universidade Federal de Sergipe. Correio eletrônico: denio_azevedo@yahoo.com.br

${ }^{3}$ Estudante do curso de Publicidade e Propaganda da Universidade Tiradentes (Unit). Correio eletrônico: arisvaldo.andrade@souunit.com.br
} 


\title{
Folkcommunication activism and Popular Cultures Resistance Practices in the Covid-19 Pandemic in Sergipe
}

\begin{abstract}
Faced with the challenges caused by the Covid-19 pandemic and the consequent migration from the way of consuming cultural practices to the virtual, the leaders of the different manifestations gained even more support in the (re)invention of cultural manife stations and in the defense of individual and collective rights. Faced with this reality, this study aims to analyze the communication and resistance practices used by popular culture activists in Sergipe from the beginning of the pandemic period to the development of this study. For this, the places of speech, the voices of media activists were respected, using the technique of semi-structured interviews with masters from popular cultures in the state of Sergipe, together with participant observations. Finally, it was verified the importance of the mobilization of activists in digital social media, a conditioning factor for the resistance of popular culture groups and the continuation of these knowledge and practices in the period worked.
\end{abstract}

KEY-WORDS

Media activism; Popular cultures; Folkcommunication; Covid-19 pandemic; Sergipe.

\section{Activismo folkcomunicacional y prácticas de resistencia de culturas populares en la pandemia Covid-19 em Sergipe}

\section{RESUMEN}

Frente a los desafíos provocados por la pandemia desarrollada por la Covid-19 y la consecuente migración hacia lo virtual, de la forma de consumir prácticas culturales, líderes de diferentes manifestaciones ganaron más apoyo en la (re) invención de expresiones culturales y en la defensa de derechos individuales y colectivos. Ante esta realidad, este estudio tiene como objetivo analizar prácticas de comunicación y resistencia utilizadas por activistas de las culturas populares em Sergipe, desde el inicio de la pandemia hasta el desarrollo de esta investigación. Para ello, se respetaron los lugares de expresión, las voces de los activistas mediáticos, a partir de la técnica de entrevista semiestructurada a maestros y maestras de las culturas populares del estado de Sergipe, junto con observaciones participantes a dichas prácticas. Finalmente, se verificó la importancia de la movilización de activistas en las redes sociales digitales, factor condicionante para la resistencia de grupos de las culturas populares y la continuidad de estos conocimientos y prácticas en el período trabajado.

\section{PALABRAS-CLAVE}

Activismo mediático; Cultura populares;Folkcomunicación; Pandemia de COVID-19; Sergipe. 


\section{RIF, Ponta Grossa/ PR Volume 19, Número 43, p.127-145, jul./dez. 2021}

\section{Considerações iniciais - Culturas Populares e a Pandemia de Covid-19}

A crise sanitária provocada pelo novo coronavírus - definida como pandemia em março de 2020 pela Organização Mundial da Saúde (OMS) -provocouo aumento da demanda por novos tipos de serviços e um avanço imensurável na tecnologia, quando as atividades remotas se tornaram alternativas para suprir as necessidades sociais frente ao isolamento físico. Assim, as mudanças que levariam anos (ou décadas) para serem implementadas adentraram repentinamente e afetaram o cotidiano social.

No interior de qualquer reflexão sobre a temática, cabe questionar o lugar das culturas populares face as transformações do século XXI, sobretudo em período de (re)invenção, com a migração para o virtual da forma de consumir práticas culturais.Como já discutido em larga escala, a interferência da tecnologia no âmbito cultural pautou, por um lado, as discussões acerca da sobrevivência dessas práticas culturais e sua submissão à lógica da Indústria Cultural (MARTÍN-BARBERO, 2010).

É fato que as culturas populares estão historicamente fadadas a enfrentar dificuldades na manutenção de suas práticas, seja pela falta de recursos e políticas públicas que melhor Ihes atendam ou pela constante invisibilização no espaço midiático. E não foi diferente no período de pandemia. O setor cultural foi um dos primeiros afetados com a crise e provavelmente um dos últimos a retomar as atividades devido às medidas de distanciamento físico.

Em Sergipe, estado que compõe uma grande diversidade de grupos e práticas culturais (AZEVEDO, 2014), importantes eventos culturais foram cancelados, como o São João, Encontro Cultural de Laranjeiras, Encontro Cultural de Japaratuba, Encontro Cultural de Tobias Barreto e o Festival de Artes de São Cristóvão. Com as atividades presencias afetadas - tão importantes no cotidiano dos seus praticantes, que além de entreter são espaços que geram renda e inclusão socioeconômica, - suas práticas se transformam e sua continuidade se torna um desafio. Somam-se, ainda,às perdas de brincantes, mestres e mestras que põe em questionamento a disseminação do conhe cimento para as próximas gerações. ${ }^{4}$

\footnotetext{
${ }^{4}$ Menção especial aos brincantes da chegança de Zé de Biné de Itabaiana/SE; a brincante Efigênia do Grupo Ciranda de Roda de Lagarto/SE; a o Mestre Rindu das Caceteiras de São Cristóvão/SE, a Dona Iolanda, mestra do Samba de Coco da Barra do Coqueiros/SE; a Dona Carmelita, Rainha das Tai eiras de Lagarto/SE; e tantos outros que se foram no período de pandemia.
}

129 | Ativismo Folkcomunicacional e Práticas de Resistência da Cultura Popular na Pandemia de Covid-19 em 


\section{RIF, Ponta Grossa/ PR Volume 19, Número 43, p.127-145, jul./dez. 2021}

Por outro lado, dá-se importância ao vínculo da localidade territorial onde se promovem as relações interpessoais e as trocas de informação no espaço virtual, o qual tornase ponto de encontro das multidões marginalizadas (MARTíN-BARBERO, 2010). Há de se considerar que os modelos de comunicação horizontais se tornam cada vez mais instrumentos de uma comunicação alternativa que busca, principalmente, atender as necessidades daqueles e daquelas que usufruem dos meios técnicos e das possibilidades do ciberespaço para expressar suas mensagens.

A concepção de comunicação em nível popular, expressas nas manifestações artesanais espontâneas, protagonizadas pelos agentes em situação de marginalidade (BELTRÃO, 1980), faz da folkcomunicação uma importante ferramenta metodológica voltada à compreensão das demandas das regionalidades na difusão de informações (SANTANA, 2020). É por esta perspectiva que Trigueiro (2006; 2018) identifica ativistas da rede folkcomunicacional que, movidos pelo interesse pessoal e coletivo do grupo social ao qual pertence, cumprem um papel de intermediário cognitivo com o intuito de suprir deficiências de suas realidades por meio da apropriação e do uso da cultura midiática.

Presume-se, portanto,que o papel dos ativistas folkcomunicacionais se tornou ainda mais fundamental para a delimitação de práticas de comunicação e resistência às limitações da pandemia da Covid-19,em vista à preservação das Culturas Populares em Sergipe.A partir desta hipótese, o presente estudo busca analisaras práticas de comunicação e resistência utilizadas pelos ativistas das culturas populares desenvolvidas entre março de 2020 e julho de 2021, momento de realização deste estudo.

Quanto às técnicas de coleta de dados, aplicou-se entrevistas do tipo semiestruturada, presenciais e remotas, a cinco ativistas do estado de Sergipe, aliadas à observação participante (PERUZZO, 2005). Para alcançar os resultados esperados, o conteúdo coletado foi interpretado à luz das categorias de análise: ativismo folkcomunicacional, práticas de comunicação e práticas de resistência das culturas populares.

Por fim, considera-se que este estudo contribui em dar respaldo ao ativismo folkcomunicacional, atualizar os conceitos folkcomunicacionais face às transformações provocadas pela pandemia da Covid-19 e fortalecer a importância das manifestações populares do estado de Sergipe. 


\section{RIF, Ponta Grossa/ PR Volume 19, Número 43, p.127-145, jul./dez. 2021}

\section{Folkcomunicação e ativismo midiático}

Por essência, a folkcomunicação baseia-se no processo de comunicação popular constituído por indivíduos em situação de marginalidade, representados por lideranças que intermedeiam a comunicação com as instituições de comunicação (mídia hegemônica). A comunicação interpessoal, neste aspecto, emprega instrumentos eficazes em um processo de comunicação muito mais complexo, perdurado em outros fluxos, e para além da ideia generalizada de "re cepção".

Nesta perspectiva, a teoria parte de enxergar e compreender os grupos marginalizados - muitas vezes distantes e não diretamente engajados aos meios de comunicação -, pela sua condição de criar, reproduzir e contestar estereótipos e hierarquias constantemente transmitidos pelos meios de comunicação de massa e propor estratégias que contribuam na supressão dos problemas da comunicação (BELTRÃO, 1980). Seria, portanto, através das expressões da cultura popular que os grupos em situação de marginalidade buscam alcançar seus direitos e o exercer da cidadania plena.

Analisar a rede de comunicação cotidiana na sociedade contemporânea requer, antes de mais nada, a compreensão da existência de um campo de lutas entre os indivíduos e as diversas instituições sociais. Essa realidade constitui a sociedade midiatizada, regida pela "tendência à "virtualização" ou telerrealização das relações humanas, presente na articulação do múltiplo funcionamento institucional e de determinadas pautas individuais de conduta com as tecnologias da comunicação" (SODRÉ, 2002, p. 21) e que cumpre um campo complexo de constantes interações que se refletem nas relações sociais cotidianas das pessoas e dos grupos.

A esse ponto de vista, Anthony Giddens (1997) justifica que a experiência global tem penetrado e impactado nos acontecimentos da vida cotidiana, seja na comunidade local ou na vida pessoal dos indivíduos. Esse processo anuncia modificações profundas nos espaços tradicionais, sejam eles arbitrários ou não, visto que as "organizações, instituições e mídia,

tecnologicamente articulados com o mercado e com os fluxos globalistas das sociedades contemporâneas" (SODRÉ, 2002, p. 153), se alimentam continuamente das culturas populares por um jogo de interesses comerciais e mercadológicos. 


\section{RIF, Ponta Grossa/ PR Volume 19, Número 43, p.127-145, jul./dez. 2021}

Faz-se importante lembrar que as transformações tecnológicas estão atreladas às velhas estruturas de poder, apesar de agilizarem a democratização (SODRÉ, 2002), que ora põe a convivência de um grupo social com outros novos grupos, ora a divisão e a invisibilização social (MARTÍN-BARBERO, 2010). Acredita-se que estes aspectos determinam a maneira como se dá o fluxo de informações. Na pandemia, observou-se o silenciamento das práticas de culturas populares em Sergipe, e confirmou-se a noção de que estas só são pautadas quando é conveniente aos detentores do espaço midiático.

Conforme Douglas Kellner (2001), na sociedade midiatizada a mídia hegemônica dita os rumos do cotidiano, como se deve ser, agir e pensar, em concordância ao sistema capitalista e as relações de poder vigente. Neste aspecto, frente ao con ceito frankfurtiano de Indústria Cultural, essa mesma mídia segue um padrão que favorece a um modelo industrial que permite a criação de mercadorias para atender aos interesses dos conglomerados transnacionais.

Face a esse conflito, Trigueiro (2018) entende que a recepção torna-se ativa, propícia a questionar as mensagens midiáticas e utilizar estratégias de leitura dos bens simbólicos e do uso dos bens materiais. Esse processo reflete-se em um campo de constantes negociações de incorporação de produtos midiáticos nas práticas cotidianas, responsáveis pelos ativismos midiático, avanços, transformações e renovações das culturas populares.

Nesta perspectiva, entende-se por ativista midiático da folkcomunicação o sujeito de referência da localidade que atua em defesa dos próprios interesses e dos interesses do seu grupo, responsável por mediar as interações entre o local e o global e suas consequentes transformações culturais por meio da formatação de práticas simbólicas e materiais para o uso na sua cotidianidade.

É um narrador da cotidianidade, guardião da memória e da identidade local, reconhecido como porta-voz do seu grupo social e transita entre as práticas tradicionais e modernas, apropria-se das novas tecnologias de comunicação para fazer circular as narrativas populares nas redes globais (TRIGUEIRO, 2006, p. 05).

A ideia de mediação põe em evidência que não existe mais receptor passivo na audiência folkcomunicacional, todos os sujeitos detêm de um grau de participação em sua localidade, visto que "[...] não existe o sujeito ausente ou sem a capacidade de decodificar o 


\section{RIF, Ponta Grossa/ PR Volume 19, Número 43, p.127-145, jul./dez. 2021}

grande volume de mensagens chegadas através da comunicação hipermediática." (TRIGUEIRO, 2006, p. 6).

No entanto, há de se considerar que a ideia de recepção ativa não necessariamente é sinônimo de ativismo. O ativista folkcomunicacional se diferencia por assumir um papel de maior respaldo no processo de comunicação, já que "sua atuação dá-se não só no movimento de resistência, mas no movimento de cumplicidade, havendo astúcia entre as lógicas das interações face a face, corpo a corpo e as lógicas das interações midiáticas." (TRIGUEIRO, 2006, p. 09).

Em atenção às demandas da sociedade midiatizada, as festas populares se reinventam a partir do importante papel dos agentes intermediários que exercem negociações nos processos de midiatização entre os significados da exterioridade - as indústrias de entretenimento e turismo, - e os das instituições locais que detém do calendário - igrejas, associações comunitárias, etc. - com o intuito de produzi-las e/ou realizá-las (TRIGUEIRO, 2018).

Diante disso, Cristina Schmidt (2006) destaca que a folkcomunicação consegue visualizar a mediação de interesses entre a cultura e o mercado na sociedade capitalista, e considera que "as estratégias de mediação precisam ser muito bem delimitadas, pois tende a esvaziar a autenticidade das relações, graças ao aparecimento de um conjunto econômico que objetiva apoderar-se de todas as manifestações da vida humana." (SCHMIDT, 2006, p. 90).

No que se refere a pensar a mediação como ativismo em defesa de direitos individuais e coletivos, o papel dos ativistas folkcomunicacionais parte de suprir deficiências de suas realidades por meio da apropriação e do uso da cultura midiática. Deste modo,

\footnotetext{
operam nas instituições locais e muito mais nas estruturas informais, espontâneas, em diversas situações, nos reclamos populares, para suprir as deficiências burocráticas e a prestação de serviços pelos setores públicos da maioria dos pequenos municípios brasileiros que, quase sempre, não atendem às suas necessidades básicas de educação, saúde, segurança, cultura, comunicação, meio a mbiente e tantas outras (TRIGUEIRO, 2006, p. 8-9).
}

Na pandemia da Covid-19 em Sergipe, realidade trabalhada neste estudo, visualiza-se ainda mais relevante o papel do ativista folkcomunicacional. Frente ao distanciamento físico, ao descaso do Estado nas mais diversas localidades marginais e a falta de atenção por parte da mídia hegemônica, esses representantes se desdobram em busca de visibilizar as 


\section{RIF, Ponta Grossa/ PR Volume 19, Número 43, p.127-145, jul./dez. 2021}

manifestações por meio da apropriação das novas ferramentas de comunicação como estratégia da inclusão so cial, em consideração a sensibilização da sociedade civil.

Neste sentido, BetaniaMaciel (2012) reforça a importância da consciência crítica das "classes dominadas" e o empoderamento que se estabelece com a valorização do saber em meio à luta pela transformação. Por esse ponto de vista, a pedagogia de Paulo Freire (1983) reforça que o processo de comunicação não é simplesmente uma transferência de saber, mas um encontro de sujeitos que põe em prática a significação dos seus significados. A mediação, neste caso, auxilia a comunicação entre duas partes, em diferentes tipos de interação, por meio de uma linguagem.

É então indispensável ao ato comunicativo, para que este seja eficiente, o acordo entre os sujeitos, reciprocamente comunicantes. Isto é, a expressão verbal de um dos sujeitos tem que ser percebida dentro de um quadro significativo comum ao outro sujeito. (FREIRE, 1983, p. 46).

A intersecção entre comunicação e ativismo possibilita pensar uma comunicação a favor da cidadania que contraria a ideia hegemônica de visibilizar apenas o caráter técnico dos dispositivos midiáticos (SODRÉ, 2002). Portanto, o processo de comunicação é considerado menos tecnicista e mais humanizado, já que os efeitos e os sentidos da comunicação não estão restritos aos meios, tal qual apontam Muniz Sodré (2002) e Jesús Martin-Barbero (2009).

O ativismo, em suma, se constrói como mecanismo de resistência aos ditames dominantes e legitima a importância da comunicação popular na sociedade midiatizada. As novas ferramentas de comunicação permitem a participação de sujeitos que, antes silenciados, ganham o domínio da comunicação (DUTRA, SANTANA, 2018) e, por vezes, assumem posição ativista no panorama cultural no qual estão inseridos. Do mesmo modo que os instrumentos de dominação se atualizam, atrelados às novas ferramentas tecnológicas, e reafirmam ainda mais o poder dos meios de comunicação, a audiência da folkcomunicação se reinventa e, a partir de sua criatividade, faz-se ainda mais atuante em resistência aos ditames dominantes.

\section{Práticas de comunicação e resistência na pandemia de covid-19 em Sergipe}

A fim de identificar as práticas de comunicação e resistência dos ativistas em Sergipe de março de 2020 até a realização deste estudo, foram entrevistas cinco lideranças que atuam 


\section{RIF, Ponta Grossa/ PR Volume 19, Número 43, p.127-145, jul./dez. 2021}

frente a grupos da cultura popular ${ }^{5}$.A escolha de cada uma delas se deu pelo reconhecimento de suas práticas de comunicação e resistência, desenvolvidas no período trabalhado. As entrevistas foram aplicadas entre os dias 01 e 16 de agosto de 2021.

Sobre as lideranças entrevistadas: 1) Maria lone do Nascimento, 68 anos, é Mestra em Artes e Cultura Popular. Atua como presidente da Associação Folclórica de Lagarto (Asflag) há mais de duas décadas, na qual lidera doze grupos folclóricos. Em 2020, recebeu o título de mestra do grupo Folclórico Parafusos ${ }^{6}$, da mesma cidade, pela Assembleia Legislativa de Sergipe $(\operatorname{ALESE})^{7}$; 2) Milton Raimundo Leite, 57 anos, é Mestre de Artes e Cultura Popular, trabalha com Culturas Populares, além de ser professor de Danças Populares. Lidera também o Reisado dos Professores há 15 anos; 3) Jose Elói dos Santos Filho, 55 anos, é marcador de quadrilha. Atua no Instituto Xerémhá 9 anos na promoção de ações para a terceira idade e como responsável pela Quadrilha Junina Peneirou Xerém. Contribui há mais de 40 anos com o movimento cultural junino; 4) Anderson Charles, 42 anos, é líder da Companhia de Artes Mafuá, um grupo de artistas que trabalha com espetáculos na promoção da cultura, das artes populares e da organização de eventos artísticos, no qual atua há 23 anos. 5) Sergio Luiz Pereira, 55 anos, atua como Presidente da Confederação Brasileira de Entidades de Quadrilhas Juninas (Confebraq) e da Liga das quadrilhas juninas de Aracaju e Sergipe (Liquajuse). É também membro do Conselho Fiscal da União Nordestina de Entidades de Quadrilhas Juninas (UNEJ) e do Conselho de Cultura de Aracaju. Faz parte do movimento cultural junino desde 1982.

As entrevistas do tipo semiestruturadasque focou nas dificuldades enfrentadas pelas culturas populares no contexto de pandemia da COVID-19. Para tal, foram classificadas três categorias de análise, baseadas nos conceitos trabalhados:ativismo folkcomunicacional, práticas de comunicação e práticas de resistência das culturas populares.

\footnotetext{
${ }^{5}$ A identificação das lideranças entrevistadas neste estudo foi consensual.

${ }^{6}$ O reconhecimento da ALESE se deve a importância de Maria Ione na continuação dos Parafusos, embora não componha o folguedo. Depois da morte do último mestre, Sr. Gerson Santos Silva, também líder da Associação Folclórica de Lagarto, Ione assumiu o cargo. Por ser mulher e não participar da dança, Eder Ferreira de Santana, mais velho brincante, tornou-se mestre também (SANTANA; DEDA, 2017a).

${ }^{7}$ A ALESE lançou um projeto Mestres da Cultura Popular que tem por objetivo reconhecer mulheres e homens que se dedicam a dar continuidade às manifestações da cultura popular de Sergipe.
} 


\section{RIF, Ponta Grossa/ PR Volume 19, Número 43, p.127-145, jul./dez. 2021}

Para auxiliar a análise das narrativas, utilizou-se a observação participante, cujo objetivo parte de inserir os pesquisadores no ambiente investigado (PERUZZO, 2005), a fim de compreender melhor as práticas de ativismo folkcomunicacional desenvolvidas. ${ }^{8}$

\section{Ativismo folkcomunicacional}

Os meios de comunicação exercem influência significativa na sociedade, a partir do seu papel informativo e de influência no cotidiano da vida social. No período de pandemia da COVID-19, ensejou-se que o espaço midiático atuasse não só no enfreamento da disseminação do vírus, mas também no fortalecimento do âmbito social- e aqui faz-se importante lembrar das culturas populares.

No entanto, de acordo com o ativista Milton Raimundo Leite, as culturas populares não ganharam a visibilidade almejada."Geralmente a mídia sergipana não comenta, divulga ou considera as manifestações populares identitárias do estado". Já para a ativista Maria lone Nascimento, as culturas populares só foram lembradas no período de divulgação da Lei Aldir Blanc, mas nada além disso - a mestra se referiu às emissoras de rádio de Lagarto e aos meios de comunicação de maior destaque em Sergipe, localizados em Aracaju.

Diante dessa realidade, destaca-se a importância dos ativistas folkcomunicacionais na luta pelacidadania, necessária para o enfrentamento aos conflitos da esfera pública, especificamente na falta de visibilidade no espaço midiático sergipano. Evidencia-se na retórica dos ativistas a necessidade de atuação das Culturas Populares e do resgate dos valores culturais, ambos necessários para o exercer da cidadania.

Por unanimidade, todas as lideranças apontaram que os meios de comunicação poderiam dar projeção às culturas populares no período de crise. Milton Raimundo Leite lembra da importância no processo de interação da mídia com os praticantes, mas que, infelizmente, não há espaço para isso. "Se desempenhassem suas funções sociais de divulgar, difundir, propagar, multiplicar, os meios de comunicação criariam uma ponte entre comunidade e brincantes promovendo saberes e fazeres, estimulando o reconhecimento e a identidade cultural".

\footnotetext{
${ }^{8}$ A observação participante aconteceu durante a execução das lives e oficinas desenvolvidas pelas lideranças no período estudado.
} 


\section{RIF, Ponta Grossa/ PR Volume 19, Número 43, p.127-145, jul./dez. 2021}

Além do aspecto comunicacional, a papel dos ativistas folkcomunicacionais se pautam pelas necessidades sociais e culturais dos grupos em que atuam. As lideranças reforçaram a importância da Lei no 14.017 de 29 de junho de 2020, denominada de Lei Aldir Blanc ${ }^{9}$, elaborada pelo Congresso Nacional, que auxiliou artistas e centros culturais através de editais públicos, principalmente a lidar com a dificuldade financeira, conforme destacou em entrevista o ativista Sergio Luiz Pereira.

De acordo com a ativista Maria Ione do Nascimento, o auxílio foi primordial para a manutenção dos grupos e artistas populares de Lagarto e asua liberação se deve, principalmente, à existência do Conselho Municipal de Cultura de Lagarto ${ }^{10}$. Em suas palavras:

eu não sei como iria ser não, porque aqui eu tenho internet, eu tenho contadora pra pagar, e a gente tem despesas, mesmo sem tá movimentando a gente tem despesa. [...] Os músicos, que foi uma situação terrível que eles passaram, o zabumbeiro mesmo que não tem trabalho.

Embora existam ações desenvolvidas em atenção à cultura popular no estado de Sergipe, estas não foram suficientes, o que necessariamente exigiu atitudes mais incisivas no que se refere a busca por alternativas viáveis. Os ativistas entendem que a lei sozinha não é satisfatória se não houver participação. Em Aracaju, conforme os ativistas Milton Raimundo Leite e José Elói Santos Filho, os editais amenizaram a situação dos grupos e artistas populares, mas a distribuição aconteceu de forma limitada. Para José Elói Santos Filho: "É lamentável, pelo que soube em relação aos valores, que muito do dinheiro foi doado pelo governo federal e os governos municipais e estadual limitaram as contas".

Além disso, a forma como os editais foram desenvolvidos se tornou um empecilho na hora da inscrição e não contemplou a maioria dos grupos das culturas populares, já que exigia conhecimento técnico que nem todos os praticantes possuem. Este fato demonstra que as políticas devem ser pensadas de acordo com a realidade dos grupos a que se destina, o que, na perspectiva da folkcomunicação, se constitui com a atenção e a valorização do

\footnotetext{
${ }^{9}$ Para ter direito à renda emergencial da Lei Aldir Blanc, exigia-se atuação social ou profissional nas áreas artística e cultural, pelo menos 24 meses antes de sua publicação. Cada estado criou seu próprio cronograma e uma dinâmica para atender o setor cultural.

${ }^{10}$ O conselho foi criado por lei em 22 de dezembro de 2011, com o objetivo de prestar consultoria e assessoramento na formulação de políticas públicas de cultura, junto à Administração Pública do município, mas só em 2019 foi instituído oficialmente.
} 


\section{RIF, Ponta Grossa/ PR Volume 19, Número 43, p.127-145, jul./dez. 2021}

conhecimento e dos significados de cunho popular para total eficiência do ato comunicativo nas propostas de políticas públicas. De acordo com Milton Raimundo Leite,

quando falamos em editais é necessário entender que o conhecimento técnico exigidos nem sempre é conhecido pelos mestres, por conseguinte, observa-se dificuldade na inscrição, na montagem dos projetos e no cumprimento do prazo de entrega das propostas.

Desse modo, a relevância dos ativistas da folkcomunicação se baseia, principalmente, na necessidade de suprir as deficiências enfrentadas pelas Culturas Populares. É por esse entendimento que se faz importante destacar as práticas de comunicação como iniciativas de ativismo, sustentadas por visões dos seus praticantes em busca de uma esfera pública alternativa, favorável ao popular.

\section{Práticas de Comunicação}

As mídias digitais se tornaram espaços de divulgação e reconhecimento cultural, e demonstram que os grupos culturais não mais dependem dos meios de comunicação tradicionais para uma efetiva participação na sociedade, fato que ganhou ainda mais impulso na pandemia.Para o ativista Sergio Luiz Pereira: "Nós trabalhamos muito a questão da internet, as nossas redes sociais fizeram a diferença. Nós nos descobrimos, né, descobrimos muita coisa, nos viramos nos trinta realmente".

Essas interações funcionaram como estímulos para a manutenção das práticas e ampliaram a visibilidade de grupos de culturas populares. Percebe-se também que as mídias digitais serviram como ampliadoras dos gritos de lutas e das causas das culturas populares.Sergio Luiz Pereira ressalta que

hoje em um clique recordações se destacam nas redes sociais como aconteceu durante vários meses, quando pessoas postando e falando dos encontros culturais que participaram criaram movimentos para estimular grupos a manterem suas atividades, incitaram planos para tempos posteriores.

Tratam-se de manifestações comunicacionais que assumem o propósito de fazer ecoar mensagens de contestação ao silenciamento na mídia sergipana e à falta de políticas que atendam de maneira mais efetiva as Culturas Populares. "Nessa nova roupagemdas redes foi possível realizar e assistir a várias lives sobre diversos temas dentro dacultura popular, permitindo que brincantes e mestres se manifestassem sobre suasproduções, deixando acesa 


\section{RIF, Ponta Grossa/ PR Volume 19, Número 43, p.127-145, jul./dez. 2021}

a chama do saber popular", conta Milton Raimundo Leite. A mesma realidade é apresentada por Maria lone do Nascimento: “Eu quedivulgo as coisa dos grupos, porque se não fosse o Instagram, o Facebook, que eu bototudo pro povo ver que existe, né?".

Ainda que não haja total conhecimento sobre as plataformas, a busca por estratégias foi intensa e refletiu nas formas de atuação. Para José Elói Santos Filho, as mídias digitais não são as soluções para todos os problemas apresentados, mas serviram como "um paliativo para a cultura, precisamos nos reinventar e o Instagram e YouTube por exemplo, com certeza a partir do conhecimento das suas funcionalidades foi muito bacana, procuramos aprender e [as mídias citadas] contribui com a disseminação da cultura".

Naturalmente, a situação de distanciamento físico provocou transformações na interação e no entretenimento. O desenvolvimento de atividades no âmbito virtual não era novidade, mas com a pandemia a adaptação das culturas populares a esse espaço foi necessária. Entende-se que é justamente em momentos como esse que os ativistas folkcomunicacionais ganharam respaldo no processo de comunicação.

Em busca de entender um pouco mais sobre essa relação, a ativista Maria lone do Nascimento ressalta que organizou a transmissão de livesatravés do recurso de transmissão ao vivo do Instagram. Só em 2020 foram nove atividades ao vivo, em períodos específicos. Em 2021 essas atividades se restringiram ao período junino, visto que o aumento da disseminação do vírus em Sergipe inviabilizou o retorno presencial dos festejos. Todas as apresentações foram exibidas e registradas no Instagram da Asflag. Os equipamentos ficaram a cargo dos brincantes, que utilizaram seus próprios smartphones. Sergio Luiz Pereiratrabalhou com a mesma estratégia, e ainda abriu o próprio espaço cultural para que os filiados pudessem participar das atividades.

Por outro lado, em um cenário de complexidades - dificuldades financeiras, a perda e o afastamento de alguns brincantes -, a prática intensiva se constituiu também como fator de desinteresse e falta de ânimo. Milton Raimundo Leite destaca que "[...] estamos a um ano e oito mês em encontros online, cujas participações são menos efusivas e é mais difícil manter a concentração dos participantes". Enquanto as atividades eram desenvolvidas remotamente, muitos dos brincantes apresentaram indisposição para ensaios e isso causou desestimulo para a continuidade de muitas manifestações.

139 | Ativismo Folkcomunicacional e Práticas de Resistência da Cultura Popular na Pandemia de Covid-19 em 


\section{RIF, Ponta Grossa/ PR Volume 19, Número 43, p.127-145, jul./dez. 2021}

Por fim, percebe-se que frente ao descaso do Estado, no que se refere a falta de políticas efetivas e àinvisibilização na mídia Sergipana, o ativismo se tornou primordial para se pensar em estratégias de resistência em vista à continuação das culturas populares na pandemia de Covid-19.

\section{Práticas de Resistência}

O cenário de pandemia demonstrou que as culturas populares, de fato, seguem fadadas a depender da vontade das ações políticas para ganhar reconhecimento. É nesse sentido que emergem as práticas de resistências dos ativistas folkcomunicacionais. Assim, é importante destacar que a ideia de resistência na perspectiva do ativismo folkcomunicacional é expressa não só como a capacidade dos indivíduos sociais em opor-se ao sistema social vigente, mas também de luta em defesa de seus interesses.

Questionados sobre o que seria preciso para mudar a atenção do poder público em relação as culturas populares, principalmente no período de pandemia, as lideranças enfatizama necessidade de colocar a preservação da cultura local comoaspecto central das políticas culturais. Para isso, cabe reformar políticas sociais e mudar as prioridades governamentais, a fim de viabilizar o processo de identificação e valorização cultural. No ecossistema criativo, as políticas públicas de cultura e a relação com as indústrias criativas demonstram inúmeras possibilidades de manutenção dos saberes e fazeres das práticas de culturas populares. A ausência de planejamento e de ações para o setor é um desrespeito aos praticantes desses saberes e fazeres e ao patrimônio cultural imaterial dos diferentes grupos sociais. Para o ativista Milton Raimundo Leite,

[...] é preciso respeito a todos, principalmente aos mestres, muitos são trabalhadores rurais, carentes de políticas sociais, cujas dificuldades e a falta de apresentações principalmente nesse período pandêmico repercute em brincantes e mestres dependentes da empatia de pessoas de suas comunidades ou de fora delas. (LEITE, Informação oral, 2021).

Por esse ponto de vista, o ativista Elói Santos Filho reforça a necessidade da manutenção das políticas existentes, de revisitar o que já tem sido feito, analisar seus efeitos e estabelecer vínculos com a comunidade a que se destina. Quando fala sobre a necessidade dessas políticas públicas para o setor de práticas juninas, Jose Elói Santos Filho afirma: "Então as políticas públicas, acho que seria permanentes e específicas, por exemplo, já existe um 


\section{RIF, Ponta Grossa/ PR Volume 19, Número 43, p.127-145, jul./dez. 2021}

projeto da prefeitura, mas como é a funcionalidade deles? E outras coisas são as estratégias que dentro do movimento junino temos dificuldades para desenvolver".

Em Lagarto, como afirmou Maria Ione do Nascimento, a inexistência de políticas culturais não é novidade. A falta de incentivo por parte da prefeitura, independente da gestão, ainda é uma realidade. Por anos os grupos enfrentam desprezo em muitas das atividades festivas da cidade, atrasos no pagamento de suas apresentações, e limitações no auxílio transporte, que nem sempre é imediato e efetivo. A ativista continuou a defender os direitos dos grupos folclóricos, seja na Asflag ou no conselho de cultura.

Em resistência ao cenário pandêmico, Milton Raimundo Leite e José Elói Santos Filho promoveram oficinas de danças - algumas delas incentivadas pela Lei Aldir Blanc -, com o auxílio de equipamento próprio para divulgação. Ambas foram pensadas para ensino remoto, através da plataforma Google Meet, porém, devido a necessidade da vivência,foram realizadas presencialmente, com o cumprimento de todo os protocolos sanitários.

O primeiro ministrou a oficina 'Vivência nas danças populares de Sergipe', que teve com objetivo apresentar danças de Sergipe como, por exemplo, o reisado, a quadrilha junina e o samba de coco. A metodologia mesclou teoria e prática. À medida que se contava a história, os participantes executavam os movimentos de corpo. Já José Elói dos Santos Filho ministrou a oficina de 'Xaxado Xerém', que teve como intenção apresentar técnicas de Xaxado. 0 ativista conduziu a oficina a partir da apresentação dos movimentos e sua influência dos passos e suas variações. No final da oficina, que foi desenvolvida em cinco dias, houve a apresentação de dois grupos de xaxado.

As atividades demonstraram a importância da vivência e a carência do público no que se refere ao reconhecimento das danças e do saber cultural de Sergipe; se tornaram relevantes por possibilitar a troca de conhecimento e experiências, além de caracterizarem como alternativas de enfrentamento à pandemia.Neste ínterim, as ações demonstram, sobretudo, a capacidade das culturas populares em estabelecer estratégias de defesa e articulação para se manterem vivas.

Além das atividades citadas, José Elói Santos Filho conta que participou, junto aos marcadores, da elaboração de um material para as quadrilhas juninas, que buscou contemplar as necessidades dos quadrilheiros no período vigente. Outros se dedicaram a participar de 


\section{RIF, Ponta Grossa/ PR Volume 19, Número 43, p.127-145, jul./dez. 2021}

reuniões e levantar questionamentos aos representantes políticos. Sergio Luiz Pereira ressalta a politização desses grupos e as suas práticas de resistência,

eu não participei de manifestações em via pública, mas a gente se posicionou, né, contra os valores iniciais que os estados e municípios ofereceram para nossas quadrilhas juninas. [...] Nós fomos juntos aos órgãos público estadual e lá nós conseguimos o direito de que nós mesmo fizesse o nosso próprio projeto, né? Poxa, um projeto que beneficiasse as quadrilhas juninas. [...] Então nós mesmo criamo o nosso próprio edital. [...] Não precisamos brigar, mas nos manifestamos sim.

Anderson Charles participou de reuniões, fez parte da escrita e construção de projetos para os editais mencionados, produziu e coordenou ações de luta para diferentes grupos das culturas populares. Já a atuação de Milton Raimundo Leite se concentrou no contato com as pessoas diretamente relacionadas ao âmbito cultural de Sergipe e, principalmente, de Aracaju. Dentre uma das discussões, este ativista lembra do projeto de auxílio emergencial destinado a mestres e mestras das culturas populares, proposta ainda em discussão, que será entregue à Assembleia Legislativa do Estado de Sergipe para apreciação. ${ }^{11}$

Por fim, as medidas tomadas pelas lideranças demonstram capacidade argumentativa de exprimir opiniões e anseios pelo reconhecimento e aceitação, principalmente em um cenário de desorientação.Percebe-se a responsabilidade dos mestres e mestrasdas Culturas Populares em manter a união de seus membros e a continuidade da prática diante de políticas pouco efetivas e das limitações causadas pela falta de reconhecimento na sociedade que atuam (SANTANA; DEDA, 2017a, SANTANA; DEDA, 2017b).

\section{Considerações finais}

As reflexões demonstram a necessidade de sobrevivência das culturas populares, face a falta de recursos e políticas públicas que melhor lhes atendam e pela constante invisibilidade no espaço midiático, além das limitações impostas pela pandemia da Covid-19. O papel dos ativistas da folkcomunicação tornou-se ainda mais significativo, tanto para suprir

\footnotetext{
${ }^{11}$ Trata-se de um projeto de lei que tramitou na ALESE e que foi rejeitado pelo governo depois de ser aprovado pelo Conselho de Cultura. A minuta solicita a implementação do auxílio mensal de dois salários mínimos para mestres e mestras, reconhecidos pela comunidade e pelo trabalho desenvolvido, que têm passado dificuldades para sobreviver. Atualmente o projeto de lei será apresentado novamente na ALESE com os devidos recursos e aprovação dos deputados.
} 


\section{RIF, Ponta Grossa/ PR Volume 19, Número 43, p.127-145, jul./dez. 2021}

as necessidades de comunicação quanto para aliviar os impactos do período e dar projeção as culturas popularesde Sergipe.

Os relatos comprovamque a utilização das mídias sociais digitais foi uma estratégia fortalecedora de ativismo folkcomunicacional e se tornou fator condicionante para a continuação das manifestações populares no período trabalhado. As mobilizações dos ativistas sergipanos, por meio da difusão de mensagens em canais como YouTube, Instagram e Facebook, foram relevantes na execução das práticas de resistência e denunciam o descaso por parte das políticas municipais e estaduais. Além disso, refletem a importância no reconhecimento e valorização cultural do estado de Sergipe.

Infere-se, portanto, que a comunicação do povo tem se reconfigurado e ganha ainda mais relevância na sociedade midiatizada. Apesar de nem sempre surgir da imaginação e da espontaneidade, já que cada vez mais sofre forte interferência de condicionamentos socioculturais, se envolve com a cultura digital e garante mobilizações sem perder seu caráter popular. Destaca-se a relevância das mídias digitais, enquanto espaços de suporte e disseminação popular, e dos ativistas midiáticos da folkcomunicação. 


\section{RIF, Ponta Grossa/ PR Volume 19, Número 43, p.127-145, jul./dez. 2021}

\section{Referências}

AZEVEDO, D. S.Turismo, Patrimônio Cultural e Identidades Consumo:construindosergipanidades. 2014. Tese (Doutorado em Sociologia) - Universidade Federal deSergipe, São Cristóvão, 2014.

BELTRÃO, L. Folkcomunicação: a comunicação dos marginalizados. São Paulo: Cortez, 1980.

DUTRA, A.; SANTANA, F. M. Marginalizados online: da teoria de Luiz Beltrão à Sociedade em Rede. In: CONFERÊNCIA BRASILEIRA DE FOLKCOMUNICAÇÃO, 19., 2018, Parintins. Anais [...]. São Paulo: Rede Folkcom, 2018.

FREIRE, P. Extensão ou Comunicação? São Paulo: Paz e Terra, 1983.

GIDDENS, A. A vida em uma sociedade pós-tradicional. In: BECK, U.; GIDDENS, A.; LASH, S. Modernização reflexiva: política, tradição e estética na ordem social moderna. São Paulo: Editora da Universidade Estadual Paulista, 1997, p. 73-134.

KELLNER, D. A Cultura da Mídia. Bauru: Edusc, 2001.

MARTIN-BARBERO, J. Dos meios as mediações: comunicação, cultura e hegemonia. 6 ed. Rio de Janeiro: Editora UFRJ, 2009.

MARTÍN-BARBERO, J. Globalização comunicacional e transformação cultural. In: MORAES, D. (Org.). Por uma outra comunicação: mídia, mundialização cultural epoder. 5 ed. Rio de Janeiro: Record, 2010, p. 57-86.

PERUZZO, C.M.K. Observação participante e pesquisa-ação. In: DUARTE, J.; BARROS, A. (Orgs.). (Org.). Métodos e Técnicas de pesquisa em comunicação. São Paulo: Atlas, 2005, p. 125-145.

SANTANA, F. M. O Caranguejo e a construção da identidade cultural de Ara caju: uma análise folkcomunicacional. 2020. Dissertação (Mestrado em Comunicação Social) - Universidade Metodista de São Paulo, São Bernardo do Campo, 2020.

SANTANA, F. M.; DEDA, T. A. A Folkcomunicação a partir do grupo folclórico Parafusos. In: CONGRESSO DE CIÊNCIAS DA COMUNICAÇÃO DA REGIÃO NORDESTE, 19., 2017, Fortaleza. Anais [...]. São Paulo: Intercom, 2017b.

SANTANA, F. M.; DEDA, T. A. A influência do líder de opinião nas ressignificações do grupo folclórico Parafusos. In: CONFERÊNCIA BRASILEIRA DE FOLKCOMUNICAÇÃO, 18., 2017, Recife. Anais [...] São Paulo: Rede Folkcom, 2017a.

SCHMIDT, C. Folkcomunicação. In: SCHMIDT, Cristina (org). Folkcomunicação na arena global: avanços teóricos e metodológicos. São Paulo: Ductor, 2006, p. 89-100.

SODRÉ, M. Antropológica do Espelho: uma teoria da comunicação linear e em rede. Petrópolis: Editora Vozes, 2002.

TRIGUEIRO, O. M. O ativista midiático da rede folkcomunicacional. Revista Internacional de Folkcomunicação, Ponta Grossa, v. 4, n. 7, p. 1-13, jan./jun. 2006. 
RIF, Ponta Grossa/ PR Volume 19, Número 43, p.127-145, jul./dez. 2021

TRIGUEIRO, O. M. Os agentes intermediários culturais e os processos de atualização na folkcomunicação, Revista Internacional de Folkcomunicação, Ponta Grossa, v. 16, n. 37, p. 84100, jul./dez. 2018. 